\title{
РЕЦЕНЗИЯ НА СБОРНИК: М.В. СТАНЮКОВИЧ, А.К. КАСАТКИНА (РЕД.) «МУЗЕЙНЫЕ КОЛЛЕКЦИИ И СОВРЕМЕННАЯ КУЛЬТУРА НАРОДОВ ИНДОНЕЗИИ, МАЛАЙЗИИ, ФИЛИППИН, ОКЕАНИИ». СПБ: МАЭ РАН, 2018
}

\begin{abstract}
В новый сборник МАЭ (Кунсткамера) РАН “Музейные коллекции и современная культура народов Индонезии, Малайзии, Филиппин, Океании” вошли статьи по этнографии и этноботанике указанного региона, а также по истории австронезийских музейных коллекиий МАЭ РАН, с особым вниманием к судьбам их создателей. Авторы статей - сотрудники отдела Австралии, Океании и Индонезии МАЭ РАН, являющегося центром австронезийских полевых исследований в России.
\end{abstract}

Ключевые слова: этнография Австронезии, российская этнография, музейная коллекция, полевые исследования, Кунсткамера, Индонезия, Малайзия, Филиппины, Океания

Новый выпуск сборника МАЭ РАН по австронезистике представляет результаты исследований малайско-индонезийского региона (включая Филиппины) и Океании по трем направлениям - полевому, архивному и мемориальному.

Первый раздел издания - "Полевики о своих и чужих коллекциях" — открывает статья океанистки А.А. Лебедевой “Ткачество в Микронезии (исторический аспект, полевые и музейные материалы)”. Автором было проведено полевое исследование ткацкого искусства Западной Микронезии, уникального явления для региона Океании, где в основном встречается выделка нетканой материи-тапы из обработанного луба. В статье представлен анализ полевых и музейных материалов, демонстрирующих особенности данной технологии в Микронезии и на северо-востоке Меланезии. Однако, с точки зрения карты бытования данного ремесла в регионе, было бы полезным включить в статью и местные названия ряда предметов (станок, рама, полотно, брусья для натяжения основы и т.п.). Наряду с ткачеством как маркером разделения Микронезии в культурном отношении на восточную и западную части, А.А. Лебедева рассматривает и другие важные факторы формирования региона (экогеографический, этноботанический, этнолингвистический). Опираясь на комплекс данных и приняв во внимание особенности мореплавания микронезийцев (подроб.: Лебедева 2013), автор подвергает критическому анализу существующие теории заселения западной и восточной частей региона. В статье обосновывается предполо-

Бакланова Екатерина Александровна - к.ф.н., старший научный сотрудник, ИСАА МГУ им. М.В. Ломоносова (125009 Москва, ул. Моховая, 11). ORCID: 0000-0003-1049-5812. Эл. почта: baklanova@gmail.com, http://istina.msu.ru/profile/Ekaterina_Baklanova. Baklanova, Ekaterina A. - Moscow State University (Moscow). ORCID: 0000-0003-1049-5812. E-mail: baklanova@gmail.com, http://istina.msu.ru/profile/Ekaterina_Baklanova/ 
жение об асинхронности процессов распространения ткачества в данном ареале и заселения Восточной Микронезии, что подтверждает отмечаемую современными специалистами условность традиционного деления данного региона на Меланезию, Микронезию и Полинезию (The Cambridge History 2004: 8-9).

Исследования Филиппинского архипелага представлены статьей ведущего специалиста по фольклору, антропологии и этноботанике Филиппин М.В. Станюкович «Кокосовая чарка, бамбуковый стакан. Этнография и этноботаника хмельной культуры Юго-Восточной Азии». Традиционные блюда и напитки на Филиппинах были сильно потеснены заимствованными уже в период испанского владычества XVI в. - к. XIX в. (Rodell 2002; Станюкович 2004; Бакланова 2018). Автор классифицирует виды алкоголя, характерные для ЮВА, по сырью (пальмовый сок, сок сахарного тростника, мед и фрукты, просо, рис) и по методу изготовления (сбраживание, дистилляция) и дает емкие характеристики каждого, его роли в экономике, ритуале и повседневной жизни в прошлом и настоящем. В ряде своих работ по этноботанике (напр., Станюкович 2015) автор уже отмечала, что в ЮВА многие ритуально-символические функции алкоголя делегированы бетельной смеси. В статье убедительно показано, что «жевательный» способ сбраживания сырья для хмельных напитков отсутствует в тех ареалах, где традиционно распространено жевание бетеля.

В малайзийской части первого раздела сборника представлены результаты продолжающейся работы по описанию коллекций, собранных в начале XX в. немецким этнологом А. Грубауэром в Северном Борнео (колл. МАЭ № 2286) (Касаткина 2014). В статье "К каталогу материалов Альберта Грубауэра из Северного Борнео” А.К. Касаткина не только описывает предметную коллекцию и этапы ее регистрации, но и предлагает модель аннотации предметов музейного каталога с учетом специфики российской базы данных “КАМИС” (БД). Оправданным представляется добавление графы “Этикетки”, позволяющей организовать по ней поиск в БД, а также объединение вкладок БД о музейном бытовании предмета в блок “Музейная биография". Дополняют обзорную статью по каталогу Грубауэра две заметки А.К. Касаткиной “Заколки дусунов...” и “Украшения из плодов бусенника (Coix lacryma-jobi)...” по материалам коллекции № 2286. В первой автор проводит сравнительное описание серии заколок-шпилек дусунов из нескольких деревень Северного Борнео, систематизируя в таблицах типы форм и орнаментов. Во второй заметке, наряду с описанием украшений из плодов бусенника, приведены сведения о сферах его применения в ЮВА: от блюд и напитков до украшений, в т.ч. ритуальных.

Второй раздел “Экспозиция, архив, история науки” открывает материал “Из архива МАЭ РАН: статья А.Б. Пиотровского «Игры народов Австралии и Океании»”, подготовленный Т.И. Шаскольской. Публикация включает биографическую справку об этнографе-океанисте А.Б. Пиотровском (1888-1942), его полную библиографию и текст рукописи.

В статье А.А. Лебедевой “Коллекция Отто Финша в собраниях МАЭ РАН” описана коллекция № 157, собранная в конце XIX в. О. Финшем в Океании, приводятся и сведения о политической подоплеке поездки д-ра Финша в Новую Гвинею и о том, как цинично он использовал труд Н.Н. Миклухо-Маклая. Автор высоко оценивает таксономию каталога и дает перевод с немецкого языка основных разделов описания.

Статья П.Л. Белкова "Карточные каталоги Отдела Австралии и Океании..." посвящена истории регистрации ранних (XVIII-XIX вв.) экспонатов по Океании, 
сформировавших ряд коллекций МАЭ. Автор реконструирует ход работы по музейной атрибуции предметов, выделяя в нем два периода: 1910-1930-е гг. (Б.Э. Петри, А.Б. Пиотровский, Л.Б. Панек) и 1950-1960-е гг. (Ю.М. Лихтенберг, Л.Г. Розина). Статья П.Л. Белкова представляет интерес и как источник информации об истории научной работы МАЭ РАН в ХХ в.

В индонезийском блоке раздела представлены две статьи выдающегося российского австронезиста Е.В. Ревуненковой. Первый материал посвящен макету Кунсткамеры “Традиционная каро батакская деревня", модели для которого были частью коллекций немецких собирателей Г. Мейсснера и К. Машмейера. В контексте описания уникального макета автор пишет и о работе научных сотрудников Кунсткамеры - Е.Л. Петри, Л.Э. Каруновской, В.Г. Трисман, внесших большой вклад в его подготовку и обновление. Вторая статья «“...Судьбы скрещенья” из жизни исследователей и собирателей индонезийских коллекций)» продолжает раскрывать факты научной и личной биографии этих ученых (Ревуненкова 2001), а также собирателя индонезийских экспонатов А.С. Эстрина.

Завершает сборник раздел "In Memoriam" со статьей Е.В. Ревуненковой памяти выдающегося исследователя культуры Океании Л.А. Ивановой (1941-2017) и библиографией ее публикаций, составленной Т.И. Шаскольской. Отрадно, что незаконченная книга Л.А. Ивановой “Материалы и исследования по источниковедению и атрибуции коллекций МАЭ из Океании. Часть II. Этнографическое собрание Н.Н. Миклухо-Маклая”, которой не суждено было выйти при жизни автора, в настоящее время готовится к публикации силами Е.В. Ревуненковой и Т.И. Шаскольской.

Сборник МАЭ РАН 2018 г. "Музейные коллекции и современная культура народов Индонезии, Малайзии, Филиппин, Океании” представляет собой хорошо структурированное издание, отражающее связанные с музейной тематикой направления работы отдела Австралии, Океании и Индонезии МАЭ РАН. Материалы объединяет как географическая (австронезийский регион), так и тематическая общность (страницы истории и принципы каталогизации музейных коллекций отдела); имеется богатый фото-иллюстративный материал. Сборник будет полезен не только специалистам, но и читателям, интересующимся ЮВА, Океанией и историей отечественной австронезистики.

\section{Научная литература}

Бакланова E.A. Феномен pansiteria: китаизмы и испанизмы в тагальской кулинарной лексике// Прокофьева И.Т., Карачкова Е.Ю. (ред.). Вкус Востока. Гастрономические традиции в истории, культуре и религиях народов Азии и Африки. М.: МГИМО-Университет, 2018. C. 479-491.

Касаткина А.К. Фотографии Альберта Грубауэра из Киау (Британское Северное Борнео) // В.А. Прищепова (ред.). Иллюстративные коллекции Кунсткамеры. СПб: МАЭ РАН, 2014. С. 60-82.

Лебедева А.А. Мореходное искусство народов Микронезии. СПб.: Наука, 2013. 172 с.

Ревуненкова Е.В. Россия и Индонезия в жизни голландки М.К. Йонгелинг // Кюнеровские чтения 1998-2001 г2.: кр. содерж. докл. / отв. ред. А.М. Решетов. СПб.: МАЭ РАН, 2001. C. $149-156$.

Станюкович M.B. О влиянии испанской колонизации на систему питания народов Филиппин // Проблемы этнографии и истории культуры народов Азиатско-Тихоокеанского региона / И.П. Сологуб (ред.). СПб.: Петербургское востоковедение, 2004. С. 348-364.

Станюкович М.В. (отв. ред.) Бетель, кава, кола, чат. Жевательные стимуляторы в ритуале и 
мифологии народов мира. СПб: МАЭ РАН, 2015. 347 с.

Rodell Paul A. Culture and Customs of the Philippines. Westport; London: Greenwood Publishing Group, 2002. 247 p.

Meleisea M., Linneken J. et al. (eds.) The Cambridge History of the Pacific Islanders. Cambridge: Cambridge University Press, 2004. 518 p.

\section{References}

Baklanova, E.A. 2018. Fenomen pansiteria: kitaizmy i ispanizmy v tagalskoy kulinarnoy leksike [The pansiteria phenomenon: Chinese and Spanish borrowings in the Tagalog cooking vocabulary]. In Vkus Vostoka. Gastronomicheskie traditsii v istorii, kulture i religiyakh narodov Azii i Afriki [Taste of the East. Gastronomic traditions in the history, culture and religions of the peoples of Asia and Africa], edited by I.T. Prokofeva, Ye.Yu. Karachkova, 479-491. Moscow: MGIMO-Universitet.

Kasatkina, A.K. 2014. Fotografii Alberta Grubauera iz Kiau (Britanskoe Severnoe Borneo) [Albert Grubauer's photos from Kiau (British North Borneo)]. (ed.). Illyustrativnye kollektsii Kunstkamery [Illustrative collections of the Kunstkamera], edited by V.A. Prishchepova, 60-82. Saint Petersburg: MAE RAN.

Lebedeva, A.A. 2013. Morekhodnoe iskusstvo narodov Mikronezii [Navigational art of the peoples of Micronesia]. St Petersburg: Nauka.

Revunenkova, Ye.V. 2001. Rossiya i Indoneziya v zhizni gollandki M.K. Yongeling [Russia and Indonesia in the life of Dutchwoman M.K. Yongeling]. Kyunerovskie chteniya 1998-2001 gg.: kr. soderzh. dokl. [Kuner readings 1998-2001: summary of reports], edited by A.M. Reshetov, 149-156. St Petersburg: MAE RAN.

Stanyukovich, M.V. 2004. O vliyanii ispanskoy kolonizatsii na sistemu pitaniya narodov Filippin [Upon the Influence of Spanish Colonization on Philippine Diet and Nutrition]. Problemy etnografii i istorii kultury narodov Aziatsko-Tikhookeanskogo regiona [Problems of Ethnography and the History of Culture of the Peoples of the Asia-Pacific Region], edited by I.P. Sologub, 348-364. St Petersburg: Peterburgskoe vostokovedenie.

Stanyukovich, M.V. (ed.) 2015. Betel, Cava, Cola, Chat. Chewing Stimulants in Ritual and Mythology. St Petersburg: MAE RAS, 2015. 347 p. (In Russ.).

Rodell Paul A. Culture and Customs of the Philippines. Westport; London: Greenwood Publishing Group, 2002. $247 \mathrm{p}$.

The Cambridge History of the Pacific Islanders / ed. by M. Meleisea, J. Linneken et al. Cambridge: Cambridge University Press, 2004. 518 p.

Baklanova, Ekaterina A.

Review on M.V. Stanyukovich, A.K. Kasatkina (eds.). Museum Collections and Contemporary Culture of the Peoples of Indonesia, Malaysia, the Philippines, Oceania. Saint Petersburg: MAE RAS, 2018. 240 p.

The new collection of articles published by MAE (Kunstkamera) RAS "Museum Collections and Contemporary Culture of the Peoples of Indonesia, Malaysia, the Philippines, Oceania" contains papers on the ethnography and ethnobotany of the said region, as well as on the history of the Austronesian collections of the Museum of Anthropology and Ethnography RAS. Special attention is payed to the fates of their collectors. The contributors to the book are staff of the Department of Australia, Oceania and Indonesia of the MAE RAS, which is the Russian leading center of Austronesian fieldwork research.

Key words: Austronesian ethnography, Russian ethnography, museum collection, field work, Kunstkammer, Indonesia, Malaysia, Philippines, Oceania 